\title{
Public health care in Afghanistan: An investigation in suboptimal utilization of facilities
}

\author{
Lakhwinder P. Singh $^{1^{*}}$, Anupama Sharma ${ }^{1}$, Manish Kumar ${ }^{2}$, Sidiq Shinwari $^{3}$ \\ ${ }^{1}$ International Institute of Health Management Research, Delhi, India; *Corresponding Author: lps@iihmr.org \\ ${ }^{2}$ Indian Institute of Technology, Patna, India \\ ${ }^{3}$ Afghanistan Centre for Training and Development, Kabul, Afghanistan
}

Received 14 August 2012; revised 16 September 2012; accepted 30 September 2012

\begin{abstract}
Afghanistan has made strides in increasing access to health care services since 2001 however it is still battling with poor utilization of services. In order to enhance demand for services a study was conducted to explore answers to the questions on knowledge, attitude and practices of communities in relation to healthcare services. The study design was cross-sectional qualitative spanning in six provinces representing geographical and ethno cultural regions of the country. In each of the six provinces, two districts were selected through mixed sampling technique representing urban-rural population. A total of 48 villages were selected in twelve districts. The study was conducted from September 2009 to March 2010. The study highlights poor heath seeking behavior associated with physical accessibility including high cost of transportation, socio-cultural barriers for women, awareness and trust for public health facilities. The system based issues adds to prevailing access related barriers such as privacy, efficiency and availability within health facilities; lack of female physicians and, aspects of behavior and attitude, and governance issues.
\end{abstract}

Keywords: Utilization; Women; Access; Attitude; Behavior; Socio-Cultural Barriers; Medicines; Poverty; Community

\section{INTRODUCTION}

The splurge in coordinated exit of international forces, Afghanistan's poor state of health affairs has generated sense of urgency and concerns worldwide. Despite several challenges faced by this war torn country, development has been made in access to health services and health outcomes since 2001. Empirical evidence shows that there has been a $136 \%$ increase in the number of func- tioning primary health care facilities in 2002 to 2007, rise in the proportion of facilities having female physicians, nurses, or midwives from $24.8 \%$ to $83 \%$; the prenatal care coverage increased to $32 \%$ and DTP3 coverage increased by $35 \%$ and the quality of care in publicly financed facilities has also increased by 22\% since 2004 [1]. Despite these significant improvements, most of the health indicators still hover near the bottom of international ranking. Afghanistan Mortality Survey [2] highlights increase in antenatal care from a skilled provider however, the infant mortality rate is as high as 77 deaths per 1000 births and under-5 mortality continues to be 97 deaths per 1000 births. It further illustrates the decrease in maternal mortality ratio from 1600 to 327 per 100,000 live births. National Health System Performance Assessment [3] has revealed slight improvement in pro-poor provisioning of services. Padunov [4] argues that horizontally-driven approach has not resulted in improvements of Maternal and child health indicators. The paper suggests adoption of vertical approaches for educating women and thus ensuring utilization of services. Given the situation it is necessary that MoPH addresses the barriers at the community level in order to achieve improved health outcomes through utilization of services by population who needs the most.

There were not many Knowledge Attitude and Practices (KAP) studies conducted in recent years at country levels for improving health services and communication strategies, therefore the literature available on them are scarce. KAP study on hygiene carried out by the Danish Committee for Aid to Afghan Refugees [5] indicates that information on hygiene existed in community, but is not practiced. Similarly, study on Afghanistan women perception on reproductive health conducted by IbnSina in 2002 [6] reported low knowledge on sexual and reproductive health along with prevailing socio-cultural factors, invariably influencing emergency obstetrical care and family planning. On contrary sparse information is available on community knowledge and attitude towards health services, household level practices, issues pertaining to effective referral system and service utilization 
of alternate care providers.

Henceforth, in order to determine the barriers, the Ministry of Public Health, Islamic Republic of Afghanistan decided to conduct a KAP study in early 2009. The study was mandated to find out factors responsible for the low utilization of basic health services in six representative provinces of Afghanistan, namely Kabul, Herat, Baghlan, Bamyan, Laghman and Paktya. The study explores answers to the following research questions:

- What are knowledge, attitude and practices of the people of Afghanistan regarding the utilization of health care services?

- What are the factors associated with the choice of a preferred health service provider?

- What are the barriers towards utilization of the health services that are already available?

- How can the utilization of healthcare services be optimized?

The paper attempts to answer these questions.

\section{METHODOLOGY}

The cross-sectional prospective qualitative study was conducted in Kabul, Herat, Baghlan, Bamyan, Laghman and Paktya province representing various geographical and ethno cultural regions of the country (Figure 1). In each of the six provinces two districts were selected using mixed sampling technique representing urban and rural population. Within a district two $\mathrm{CHCs}$ were selected and out of the two one was taken from the centre of the district and another from the districts' catchment area. At the level of CHC, two villages were selected. The first study site/village was selected in which that CHC itself was situated and another study site/village was selected from the catchment area of that $\mathrm{CHC}$. This way at the level of selection of study sites, priority was given to select a fair percentage of respondents from rural as well as urban areas. A total of 48 villages and 24 health facilities were selected based on a pre decided criteria in twelve districts of the selected six provinces. Four qualitative techniques were used as for data collection namely social mapping, in-depth interviews, key informant interviews and focus group discussion (Table 1). Social mapping and key informant interviews were used to understand community dynamics and health provider's networks.

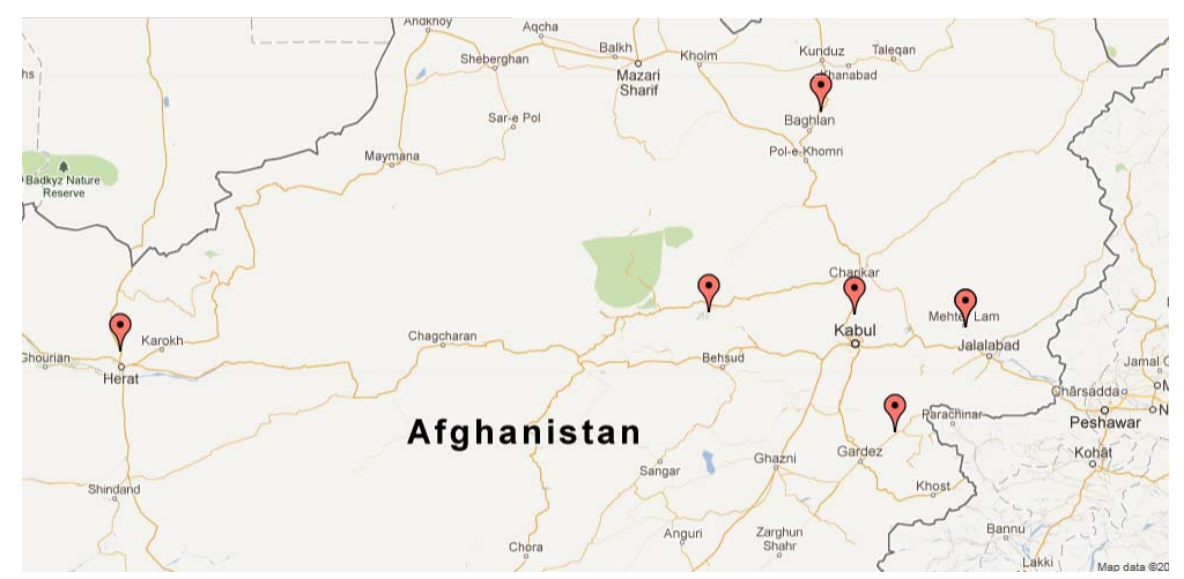

Figure 1. Details of study sites visited by survey teams for data collection. https://maps.google.com

Table 1. Details of sample size for each category of study methods.

\begin{tabular}{|c|c|c|c|c|c|}
\hline Methods & $\begin{array}{l}\text { At } 1 \text { site } \\
\text { (Village ) }\end{array}$ & $\begin{array}{l}\text { Within } 1 \\
\text { CHC }\end{array}$ & $\begin{array}{l}\text { Within } 1 \\
\text { District }\end{array}$ & $\begin{array}{l}\text { Within } 1 \\
\text { Province }\end{array}$ & $\begin{array}{c}\text { In } 6 \\
\text { Provinces }\end{array}$ \\
\hline Social Mapping (of the selected study site/village). & 1 & 2 & 4 & 8 & 48 \\
\hline $\begin{array}{l}\text { In-Depth Interview with a Mother (with atleast one surviving child under } 5 \\
\text { years of age). }\end{array}$ & 1 & 2 & 4 & 8 & 48 \\
\hline $\begin{array}{l}\text { In-Depth Interview with Head of a Household (in which there are atleast two } \\
\text { children less than } 10 \text { years of age). }\end{array}$ & 1 & 2 & 4 & 8 & 48 \\
\hline $\begin{array}{l}\text { Key Informant Interview-Type II (healthcare providers who stay near the } \\
\text { community like NGO Doctor, hakim, quake, etc.). }\end{array}$ & 1 & 2 & 4 & 8 & 48 \\
\hline $\begin{array}{l}\text { Key Informant Interview-Type III (officials at district level from health } \\
\text { education, revenue and police). }\end{array}$ & $X$ & $X$ & $\begin{array}{l}4 \text { (all district } \\
\text { level) }\end{array}$ & 8 & 48 \\
\hline $\begin{array}{l}\text { FGD with Married Men (in the age group of } 15 \text { to } 49 \text { years of age). } \\
\text { FGD with Married Women (in the age group of } 15 \text { to } 49 \text { years of age). }\end{array}$ & $\begin{array}{l}1 \text { (among men/women } \\
\text { alternatively) }\end{array}$ & 2 & 4 & 8 & 48 \\
\hline
\end{tabular}


Key Informant Interviews Type I, II and III were conducted to understand the dynamics of health seeking and issues related to access and utilization of health services from the perspective of community influencers and providers. Key informant type-I included community influencers like Mullah, Maliks and Arbabs etc. These were the people who have lived in the community all their lives and are opinion builders of the community and therefore have strong influence of practices of the community including health seeking as well as guiding the community about health services. Type-II key informants included health providers and personnel working for other public department who have strong interface with the community but mostly do not belong to the community but had been living in the area for a while and therefore developed an understanding of the community and their behavior. Type III key informants were the people living in the provincial headquarters and interact with community on long term basis and mostly come from public systems other than health department.

A total of 288 interviews and FGDs were conducted during the survey. Out of the total number of in-depth interviews, 50\% were with the mothers (who had at least one surviving child less than 5 years of age) and another $50 \%$ with the head of the households (who had at least two surviving children less than 10 years of age). Total number of key-informant interviews was 144 which were divided between key informant type-I, type-II and III respectively (Table 1). The study instruments and protocols were developed working closely with the MOPH. The same was submitted to the Ethical Committee of the Indian Institute of Health Management Research (IIHMR), the principal agency responsible for the study (along with Afghan Centre for Training and Development (ACTD) as well as Institutional Review Board (IRB) of the Ministry of Public Health. These two bodies approved the study protocol, study instruments as well as consent forms. The finalized instruments were used for collecting information. The tools were prepared in English, which were later translated into Dari/Pashto by professional translators. The study was conducted between September 2009 and March 2011 and the field work of the study was conducted between October and December 2009.

\section{RESULTS}

The results presented are based on the analyses of the original transcripts in Dari and Pashto as well as the translated version of the transcripts in English.

\subsection{Knowledge}

\subsubsection{Health Education, Literacy and Community Participation}

Health providers acknowledged that the lack of aware- ness among poor Afghanis about the health care facilities affects the service utilization adversely. Type-III respondent from Herat city explains:

Most of the elders in families have a low literacy level that causes to have their children unvaccinated. Due to their low literacy and less awareness they don't know about the benefits of vaccination. These are the reasons that they are not allowing their children to get vaccinated. Secondly people don't rely on these vaccines and they say that the vaccines are prepared in non Muslims countries.

Despite a good coverage of facilities under BPHS, utilization from rural areas was found to be low. To address this issue, providers mentioned the need of having regular Shura (the villager council) meeting and developing a specific awareness generation program for the community. Though, at many places Shura meetings are held once in a month at the facility level however these needed to scale up to other facilities.

\subsection{Attitude}

\subsubsection{Attitude and Behavior of Health Providers}

A poor and disrespectful behavior of health providers towards patients becomes another deterrent factor that discourages community from availing health services. A head of household in Laghman's Markazi district living away from the vicinity of public health facility said:

My child had diarrhea, I took him to a facility, the in charge of clinic said that there is no medicine in the clinic and he quarreled with me.

A woman respondent from a non-Markazi district of Kabul province reported:

They do not behave nicely with us, those who are with recommendation or are from their own tribes they are examined without any entry slip and the drug is also prescribed for them and given from the hospital. And those who are not with recommendation and are poor, they are driven away from the hospital. They examine one patient and if another is dying they do not look at them.

One of the health provider from a public health facility situated in the peripheral area of the provincial city in Baghlan said:

The doctor's good manner and persuasion impel people to trust and go to a public health facility every time they need any treatment, but unfortunately despite having all necessary equipments at my facility, a good number of people do not visit our facility because of unsympathetic staff.

\subsubsection{Perception on Quality of Medicines}

Many respondents across the provinces responded that the medicines distributed through public health facilities are loose and are of inferior quality. They specifically mentions that for every disease doctors at health facilities 
always prescribe same red, white and other colored loose tablets every time. One of the male respondents in Baghlan's non-Markazi district reported:

I have a daughter, who got sick. I took her to a clinic two to three times. In my first visit doctor was not available, on second visit drug was not available, then I took her to a private clinic, which prescribed some medicine and she is alright now. The public health facility gives the same tablets to all patients for every disease. A woman who was the grand mother became sick and went to clinic. The doctor given her an IV infusion contained with a lot of injection into it, the women died on spot.

A male respondent living away from public health facility in Laghman's non-Markazi district said that:

My wife was sick she was suffering from leg pain and she is not cured till now, we took her to health facility but the drugs of health facility did not work on her pain.

\subsection{Practices}

\subsubsection{Women's Autonomy}

Afghanistan is an Islamic nation, where most of the residents profess Islam and there are three major ethnic groups include Pashtoons (mostly in the Eastern and Southern region of the country), Tajik (who are mostly in Northern and Western regions) and Hazara communities (mostly central highlands but are also present in other places as well.) All three communities follow Islam and local cultural practices vary slightly from one ethic group to another.

Many examples revealed that as part of local custom women need authorization and had to be escorted by men for accessing public health facilities. During non-availability of male escort, women have to depend on traditional home based treatment. A woman respondent from the Markazi district of Laghman describes:

I am not authorized to come out from home alone, if I found someone at home than I will come with him otherwise wait to the Mercy of Almighty Allah.

On the issue a man respondent from a peripheral village in a non-Markazi district of Paktya said:

I let her (wife) to go to hospital, but with father in law, brother in law, mother in law or someone else from the family. Without Maharam (with close relatives) women cannot go to clinic.

In rural areas of study provinces, many families reported that being a Pashtoon, delivery of women outside home is considered as taboo and a matter of shame in the community. Many Pashtoon women acknowledged that though they wanted to go to health facilities for delivery, but their families did not allow them and they have opt for TBAs/mid wives at home as per custom.

A woman respondent from the peripheral village of the Markazi district of Baghlan said:
My last child was delivered at home, Pashtoons (respondent was a Pashtoon lady) do not take their women to clinics, and even my husband was not at home. When the problems get acute only then we take our women to hospital. We do not have the custom and tradition of delivering in hospital. Usually we deliver at home.

\subsubsection{Cultural Practices and Traditional Beliefs}

In certain diseases people seek traditional healers like Mullah, Hakim and others; while for other diseases they use modern medicine through public health institutions. In case the disease is chronic and results in no relief from modern medicine, people drift towards traditional healers mainly due to social and peer pressures.

A male respondent living in the Markazi district of Bamyan describes:

I have a child of five years who is paralyzed, I went to hospital and the doctors said to take him to Kabul and when I went to Kabul they said it would be treated in Germany. For full one month we were kept in hospital and went hospital to hospital, and finally they said that it cannot be treated. Then we took him to Shrine and there also he was not cured, he is still paralyzed. We took him to a Mullah, he said to do Shishdil (slaughter the lamb, the lungs of the lamb has to be passed over the abdomen of Child), we did in the same way and still my child was not cured. Again we took him to another doctor and still he has not recovered.

For treating convulsion disease, a type-III respondent from a non-Markazi district of Herat express:

One of my children was taken to a local private doctor for same problem (convulsion) and was under his treatment, but not cured. We got a lot of prayers from religious elders also. We also took him to psychiatrist doctors. As Afghanistan is religious country, people advised me to take him to Agha Saheb. I took him to Agha Saheb also, although his prayers did not mean less and had no effect. From the Holy Quran point of view, we believe that the verses of Holy Quran have effects and it is the cure for every disease. Now we have kept my child under the treatment of Agha Saheb and Doctors both. We visit the doctors when all his medicines are finished but still he is not relieved from the problem.

The community beliefs in the traditional medicine are strongly imbibed in the culture in relation to treatment of diseases such as hypertension, infertility, etc.

\subsubsection{Direct Payments and Poverty}

Although public health facilities are free from "user fees", but majority reported a considerable "out of pocket expenditure" for availing health services from public health facilities especially in case of non-availability of drugs and injections. The culture of staff demanding money as gift or nazrana, after a successful delivery (sometimes 
coarse), it discourages poor families to opt for institutional delivery, resulting in diversion to TBAs for services.

One of the local influencer from a rural area of Paktya district shares his personal experience:

There is not any expert doctor in the clinic, no enough quantity of drugs is available in the health facility and also there is no ambulance in the facility. We are not satisfied with the delivery section of the hospital. Once I had a patient in the facility and the staff asked me money for soap, shampoo and handkerchief. In the name of sweets they took 3000 Afs from me and we had to complain in this regard.

A woman respondent in a non-Markazi district of Kabul added:

When we sometimes come to clinic, the doctor says that the medicine is out of stock. When medicines are available in health facility, they prescribe it to the patients only for two or three days, but when patients come back again, they say the drug is finished. They do not prescribe more drugs like syrups and instead they prescribe more tablets.

\subsubsection{Informal Payments to Health Providers}

Some of the key respondents under this categorically raised the issue of informal understanding between public health facility doctors and private drug sellers. They acknowledged that in most urban public health facilities there is a strong association between the doctors and the private drug sellers. Most of the time doctors as perceived by patients inform them shortage of drugs or of poor quality, and hence advise them to purchase from private drug stores near the health facility, which charge exorbitantly. This has discouraged community to avail public health services for treatment.

\subsection{Facilities Based Issues}

\subsubsection{Physical Accessibility}

Respondents acknowledged that due to poor economic condition and large distance from health facilities, many Afghan families prefer to receive services from TBA. However in some obstructed pregnancy cases they have to travel to far distant hospitals. Hiring any mode of transport like car, cabs etc., cost minimum 200 Afghanis (1 US\$ $=50$ Afghanis) to 1000 Afghanis for a trip to hospital. Families unable to afford high cost of transport use other modes like donkey or donkey driven cart, which takes around four to eight hours to reach the facility.

A women respondent of Baghlan, who has been through such situation, said:

One night, my brother in law's wife fainted, we took her to a public health facility, According to her, the midwife of that facility was unable to give medicine and referred her to the higher level facility.

She added:
The facility does not have men or woman specialist doctors, option was to take her to city but we didn't have transport facility, we returned back to home.

A health provider in the non-Markazi district of Baghlan highlighted poor district transport infrastructure. He said:

I request the government to respond to the needs of the area. People of my region need a bridge to be constructed, so that they can have easy access to the clinic (public health facility). Without a bridge, people have no other choice but to travel by a vehicle using long route. At present the clinic is so far that they say to reach a clinic, it is better to die at home. Last year a sick woman was drowned into river, when she was going to the facility through the river.

\subsubsection{Condition and Functioning of Health Facilities}

Many respondents in urban areas, staying around BHC/ CHCs reported that even if staying closer to the health facility, they cannot access the same during emergency time at night because of non-availability of staff. In such emergency cases they are left with no choice but to take their women to district, provincial or private hospitals.

One of the Type-I key informant from rural area of Paktya mentions:

I do not go the public hospital, but to the private doctor because they do faster and good diagnosis. In public hospital there is big queue from morning up to 2 o'clock and there is mis-management and no drug for poor people.

Another bad experience was narrated by women from a non-Markazi district of Kabul:

The weather is cold and patients come to health facility at 7 AM from faraway places and when they arrive they are asked to receive the entry slip. After getting their entry slip patients wait for their turns, but up to 10 AM no doctor is seen (at the facility). The doctors are sitting at their homes, but the poor patients are waiting at the gate of the hospital, which sometimes causes severe damage to their health. No one pays attention to patients and when their turn arrives in the afternoon the heaters are off (during cold weather) and there is no oil in the heater. Why we are not helped?

Also, non-availability of essential drugs all the times and ambulance service is identified as significant issue by the health providers. A public health facility doctor (type-II key informant) of Kabul city reported:

In our health facility the children and mother health care is provided but there is no heated delivery room. In hot weather we do not have problem, but in cold whether we don't have heated delivery room.

A local influencer of the Markazi district in Baghlan said: 
We have a lot of problems; we don't have eye and orthopedic specialist at our facility. Once we had a patient, when he was being taken to a specialist, believe me he died on the way.

A women respondent from a peripheral village of a non-Markazi district of Baghlan said:

My last child was delivered at home during night. In clinic (public health facility) there was no doctor and the private doctor's clinics were so far away and that's why my child was delivered at home.

Many respondents also mentioned other issues such as short OPD timings at BHC/CHC of only 2 - 3 hours, huge queue of patients, poor behavior by doctors and staff, and practice of motivating patients to visit their own private clinics.

\subsubsection{Privacy during Care and Treatment}

All the respondents reported lack of basic privacy for women at public health facilities. The women are made to wait in the same waiting place/queue among men at the facility. A private health provider of a village in a non-Markazi district of Kabul reported:

Our problem is that men and woman are made to wait in one hall so no one prefers to bring their bride to the health facility and take her to the delivery room crossing through waiting men patients. There should be separate waiting areas for men and women.

\subsubsection{Non-availability of Female Physicians}

Afghanistan being a culturally sensitive country, community doesn't prefer male doctors for their women. Most of the rural area respondents in all provinces acknowledged that despite their preference for public health facility, they are unable to seek services for their women due to non-availability of female health professionals in BHC/CHCs.

One of the women respondents in a non-Markazi district of Paktya said that:

The Government should recruit woman doctor in the clinic, there should be woman vaccinator in the health facility and in order to have good health facility there should be ambulance in the health facility to refer the patients.

One of the type-III key informants from education department in Paktya said that:

In this health facility most of the deliveries are conducted but there are only midwives and no woman doctor. If here were $M D$ doctors the quality of services would be better.

Another type III key informant belonging to Police department echoed the sentiments:

The people are not educated and do not have information about the doctors. Some people go to Mullah or traditional doctor and if there is no cure with the treatment then they go to clinic and are cured here. Our health facilities are not fully equipped because there is no woman doctor and no midwives

\section{DISCUSSION}

\subsection{Service Delivery}

The first point of contact serves as mirror to the characteristics of an organization. Long waiting time, short registration time and inappropriate queue system for male and female visitors at outpatient department is a reflection on inefficiency and diminishing quality. This perpetually results in patient distress and dissatisfaction [7]. Many scientific methods are implemented among global organizations to address system issues such as application of lean theory for reducing waste and streamlining processes; queuing theory for identifying bottlenecks that cause queue such as number of registration counters, etc. which are applicable contextually [8]. Some common changes at facility like use of effective signages or implementation of token/ticketing system also, can facilitate the reduction of waiting time [9].

\subsection{Drug Effectiveness}

Loose pills and substandard quality drugs are often used synchronously especially in case of anti-malarial, tuberculosis, and antibacterial medicines and in many instances packaging and labeling is emphasized for ensuring monitoring of expiry drugs. Poor as "perceived" packaging affects the consumer perception about the efficacy of the drug. In the study participants raised concern in line with loose, same color poor quality drugs. On the other side, the drug assessment quality study conducted in 2007 highlights that the Afghanistan has very miniscule problem of substandard drugs and healthcare facilities offering basic package of health services are providing standard quality drugs to patients [10]. This draws attention to the poor perception of community on quality aspects of drugs supplied at public facilities in spite of drugs meeting quality checks. The issue perception of prescribing the same colored drug for different symptoms needs to be tackled as a priority. However, the core lies in communication between providers and stakeholders which can be strengthened by developing an effective community feedback system on health facility service quality along with effective IEC strategy [11].

\subsection{Health Workforce}

Achieving Millennium Development Goals 4 \& 5 in Afghanistan mandates the requirement of women friendly health services and unavailability of female physicians and para medics is the biggest roadblock in achieving it. Many respondents associated with community men- 
tioned the lack of skilled, specialized doctors and health professionals including female physicians. Absence of female doctors in conservative societies makes the health services inaccessible even if available. Country evaluations of disease-oriented programs have found that the lack of appropriately trained and motivated health workers is one of the impediments in improving maternal and child health [12]. The absences of well educated and efficiently managed health workers were also identified as a health systems constraint to achieve the MDGs [13]. As like other developing countries India also suffers from shortage of female doctors; the ratio is low when compared to male doctors. While on the other hand the international maternal health efforts are now focused to the provision of accessible, affordable, and quality EmOC services to save mothers' lives. The first step to address this issue in Afghanistan could be is to recognize the underlying core issues, some of which are evident in countries of similar origin like Pakistan: poor salary packages, inadequate service structure for women, doctor's willingness to work in rural areas, and security issues [14]. The World Health Report (WHR), 2006, launched the Health Workforce Decade (2006-2015) for countries to develop effective workforce strategies incorporate three core elements: improving recruitment, helping the existing workforce perform better, and reducing workforce migration [15]. In absence of truly functional private sector in Afghanistan, a long term strategy can be framed by adopting successful interventions from low-middle income countries such as Nepal mandating 2 year rural health service for scholarship, instituting a community based model of medical education and continually developing para-medical staff to support the dearth of doctors [16]. Replicating the model of integrating traditional healers in primary healthcare delivery in Afghanistan as applied by many countries can meet some of the demands of fragile system [17].

Healthcare providers though well qualified but with inappropriate behavior, discriminatory attitude and negative stereotype towards low socio-economic class in the community as evident from the findings, is a bigger setback to a functional healthcare system as all efforts will prove futile if community chose to avail services of traditional healers over public health facility. It is imperative to look deeper for exploring and identifying issues of healthcare workers attitudes, prejudices, and assumptions towards afghan community through a separate study. Multiple links between a worker behavior, organization and systemic factors defines a particular pattern of dealing with the community, such as work environment, bureaucratic framework, socio-political context, etc. [18]. These issues can be addressed through an integrated training program aiming at sensitizing health workers for providing a compassionate care and improving the interpersonal skills in a supportive motivating environment.

\subsection{Access}

WHO report on financing for universal coverage explicitly states that direct payments including doctor consultation fees, payments for procedures, medicines and other supplies, and for laboratory tests, prevent millions from accessing services and result in financial hardship and even impoverishment. It further suggests that universal health coverage to all citizens can be accelerated if reliance on direct payments is reduced [19]. Though as per constitutional provisions, all services in public setups are to be provided free of cost [20]. However, findings highlight huge out of pocket expenditure by community on transportation, medicines as well as on physician consultation. In the given situation, it can be argued that if quality of services is improved, households would be willing to pay a token amount at health facilities. Health financing provisions have been proved successful such vouchers, condition cash transfers or micro insurance schemes for covering transportation and other expenditures. Thus, similar measures can be adopted for reducing burden to poor [21].

\subsection{Community Ownership}

Providers pointed out low awareness on health some facilities took the initiative of holding villagers council meeting to spread the awareness on various health and sanitation issue. Local organizations such as shura are effective representation of community interests as the body ensures equity and justice to all villagers. However Shura has many functional and representation issues such as not mirroring the social realities due to selection bias which could result in sub-optimal identification of needs and use of resources [22]. For effective utilization of resources such as facilities to best for community and vulnerable segment of society, requires active engagement of civil bodies with local authorities at village level.

\section{REFERENCES}

[1] Ministry of Public Health, General Directorate of Policy and Planning, Monitoring and Evaluation. The Johns Hopkins University Bloomberg School of Public Health. Indian Institute of Health Management Research (2006) Afghanistan health survey. http://moph.gov.af

[2] Afghan Public Health Institute, Ministry of Public Health (APHI/MoPH) [Afghanistan], Central Statistics Organization (CSO) [Afghanistan], ICF Macro, Indian Institute of Health Management Research (IIHMR) [India], and World Health Organization Regional Office for the Eastern Mediterranean (WHO/EMRO) [Egypt] (2010) Afghanistan mortality survey. http://www.moph.gov.af

[3] Ministry of Public Health, Islamic Republic of Afghanistan, Johns Hopkins University, Indian Institute of Health Management Research. (2008) Afghanistan health sector balanced scorecard. http://moph.gov.af 
[4] Padunov, N.C. (2010) Improving the delivery of maternal health services in Afghanistan.

http://d-scholarship.pitt.edu

[5] ReliefWeb Report (2006) Afghanistan: KAP study on hygiene in Faryab baseline assessment report. Danish Committee for Aid to Afghan Refugees, Kabul. http://reliefweb.int/node/416474

[6] IbnSina, ICRH. (2002) KAP survey regarding reproducetive health. http://www.icrh.org

[7] Muhondwa, E.P.Y., Leshabari, M.T., Mwangu, N., Mbembati, N. and Ezekiel, M.J. (2008) Patient satisfaction at the Muhimbili National Hospital in Dar Es Salaam, Tanzania. East African Journal of Public Health, 5, 67-73.

[8] Rechel, B., Wright, S., Barlow, J. and McKee, M. (2010) Hospital capacity planning: From measuring stocks to modelling flows. Bulletin of the World Health Organization, 88, 632-636. doi:10.2471/BLT.09.073361

[9] Shukla, S. (2008) Streamlining OPD. http://www.expresspharmaonline.com/20080531/healthca re03.shtml

[10] Ministry of Public Health, Islamic Republic of Afghanistan, Johns Hopkins University Bloomberg School of Public Health, Indian Institute of Health Management Research (2007) Drug quality assessment study Afghanistan. http://moph.gov.af

[11] Rutebemberwa, E., Ekirapa-Kiracho, E., Okui, O., Walker, D., Mutebi, A. and Pariyo, G. (2009) Lack of effective communication between communities and hospitals in Uganda: A qualitative exploration of missing links. BMC Health Services Research, 9, 146. doi:10.1186/1472-6963-9-146

[12] Dreesch, N., Dolea, C., Dal poz, M.R., Goubarev, A., Adams, O., et al. (2005) An approach to estimating human resource requirements to achieve the millennium development goals. Health Policy and Planning, 20, 267276. doi:10.1093/heapol/czi036

\section{Abbreviations}

ACTD: Afghanistan Centre for Training and Development;

ANDS: Afghanistan National Development Strategy;

APHI: Afghanistan Public Health Institute;

ARI: Acute Respiratory Infection;

BCC: Behaviour Change Communication;

CHW: Community Health Worker;

FGD: Focused Group Discussion;

GCMU: Grant and Contract Management Unit;

HSSP: Health System Strengthening Project;

ICRC: International Centre for Reproductive Health;

IEC: Information Education Communication;

IIHMR: Indian Institute of Health Management Research;

IMCI: Integrated Management of Childhood Illnesses;
[13] Travis, P., Bennett, S., Haines, A., Pang, T., Bhutta, Z., Hyder, A.A., et al. (2004) Overcoming health-systems constraints to achieve the millennium development goals. The Lancet, 364, 900-906. doi:10.1016/S0140-6736(04)16987-0

[14] Ali, M., Bhatti, M.A. and Kuroiwa, C. (2008) Challenges in access to and utilization of reproductive health care in Pakistan. Journal of Ayub Medical College, Abbottabad, 20, 1-7.

[15] World Health Organization (2006) Working Together for health: The world health report. www.who.int/whr

[16] Shankar, P.R. (2010) Attracting and retaining doctors in rural Nepal. Rural and Remote Health, 10, 1-7. http://www.rrh.org.au

[17] Jha, N. and Kannan, A.T. (2006) Utilizing traditional healers in primary health care. Regional Health Forum, 5 38-40.

[18] Jamison, D.T., Breman, J.G., Measham, A.R., Alleyne, G., Claeson, M., Evans, D.B., et al. (2006) Disease control priorities in developing countries. Oxford University Press, Oxford. doi:10.1596/978-0-8213-6179-5/Chpt-71

[19] World Health Organization (2010) World health reporthealth systems financing: The path to universal coverage. World Health Organization, Geneva. http://www.who.int/whr/2010/en/index.html

[20] Ministry of Justice, Islamic Republic of Afghanistan (2012) The constitution of Afghanistan, fundamental rights and duties of citizens, Chapter 2, Article 52. http://moj.gov.af/en

[21] DFID (2011) DFID cash transfers literature review, policy division. http://www.dfid.gov.uk

[22] Brick, J. (2008) The political economy of customary village organizations in rural Afghanistan. Presented for the Annual Meeting of the Central Eurasian Studies Society, Washington DC. http://www.bu.edu/aias/

KAP: Knowledge Attitude Practice;

MDG: Millennium Development Goals;

MoPH: Ministry of Public Health, Islamic Republic of Afghanistan;

PHD: Provincial Health Director;

PPH: Post Partum Haemorrhage;

RTI: Reproductive Tract Infection;

STI: Sexually Transmitted Infection;

STD: Sexually Transmitted Diseases;

TBA: Traditional Birth Attendant;

UTI: Urinary Tract Infection;

FSAU: Food Security Analysis Unit (in Somalia, managed by UNFAO);

UNFAO: United Nations Food and Agriculture Organization. 